\title{
Differential Microvasculature Dysfunction in Living Kidney Donor Transplant Recipients: Nondialyzed versus Dialyzed Chronic Kidney Disease Patients
}

\author{
Ada W.Y. Chung ${ }^{a}$ H.H. Clarice Yang ${ }^{a}$ Mhairi K. Sigrist ${ }^{b} \quad$ Elliott Chum ${ }^{b}$ \\ Anthony D. Booth ${ }^{\mathrm{b}}$ William A. Gourlayc ${ }^{c}$ Adeera Levin ${ }^{b}$ \\ ${ }^{a}$ Department of Cardiovascular Science, Child and Family Research Institute, and Divisions of ${ }^{b}$ Nephrology \\ and 'Urologic Science, University of British Columbia, Vancouver, B.C., Canada
}

\section{Key Words}

Vasocontraction - Endothelium-dependent relaxation •

Arterial stiffness $\cdot$ Pulse wave velocity $\cdot$ Microcirculation

\begin{abstract}
We hypothesized that there was differential vasomotor dysfunction in the microcirculation between nondialyzed and dialyzed chronic kidney disease (CKD) patients. During live donor kidney transplantation procedures, skin arterioles (SkA; internal diameter $=120 \pm 5 \mu \mathrm{m})$ from donors $(n=27)$ and recipients (nondialysis $=15$; dialysis $=20$ ) were dissected from the abdominal wall at the incision site. In vivo aortic pulse wave velocity (PWV) was also measured. In the in vitro isometric force measurement, nondialyzed SkA exhibited comparable contraction to donor SkA, whereas dialyzed SkA had 60 and $40-50 \%$ increase in contraction in response to depolarization and agonist (that is, phenylephrine, serotonin and endothelin-1) stimulation, respectively. The acetylcholine-induced relaxation in the nondialyzed SkA was decreased by $50 \%$ compared with dialyzed SkA. However, pre-incubation with superoxide dismutase greatly enhanced the relaxation response in the nondialyzed, but not in the dialyzed SkA and donor SkA. Pre-incubation with $N^{G}$ nitro-L-arginine methyl ester (L-NAME) elevated the resting
\end{abstract}

tension and left-shifted the concentration response curve of phenylephrine-stimulated contraction in the donor-SkA. L-NAME only increased the resting tension in the nondialyzed vessel. In vitro stiffness positively correlated with PWV $\left(R^{2}=0.302, p=0.001\right)$, and dialyzed SkA was $60 \%$ stiffer than nondialyzed and donor SkA. The acetylcholine relaxation was negatively correlated with PWV in donors and recipients $\left(R^{2}=0.282, p=0.01\right)$. In conclusion, we have uniquely demonstrated differential microvasculature dysfunction between nondialyzed and dialyzed CKD patients.

Copyright $\odot 2009$ S. Karger AG, Basel

\section{Introduction}

There is an increasing recognition that the adverse clinical outcomes associated with chronic kidney disease (CKD) are primarily due to cardiovascular disease. Both large and small vessel disease (such as diabetes mellitus and hypertensive nephrosclerosis) have been described in CKD $[1,2]$. Furthermore, the processes of arteriosclerosis and atherosclerosis are both present in CKD, with the former often being more prominent than the latter. The presence of structural and functional alterations in the microcirculation could be considered as an important

\section{KARGER}

Fax +41613061234 E-Mail karger@karger.ch www.karger.com
(C) 2009 S. Karger AG, Basel

$1018-1172 / 10 / 0472-0128 \$ 26.00 / 0$

Accessible online at:

www.karger.com/jvr
Dr. Ada W.Y. Chung

Department of Cardiovascular Science

Child and Family Research Institute, University of British Columbia

Room 2099, 950 28th W Ave, Vancouver, B.C. V5Z 4H4 (Canada)

Tel. +1 604875 3852, Fax +1 604875 3120, E-Mail adawingyee@yahoo.ca 
link between renal failure and hypertension, ischemic heart disease, and heart failure.

The microvasculature acts on blood pressure propagation and is becoming more evident as the primary determinant of long-term vascular resistance [3, 4]. Functional and mechanical changes in microvasculature have been shown to be correlated with risk for cardiovascular morbidity and mortality [5]. Recent data have also suggested that alterations in small resistance artery morphology may represent the most prevalent and the earliest form of target organ damage at the cardiac level [6] in essential hypertension [7]. The endothelium, by secreting numerous vasoconstrictors or vasodilators, plays an important role in the control of vascular structure and tone [8]. Studies have described reduced endothelium-derived nitric oxide (NO) bioavailability as a contributor to increased arterial stiffness, and elevated pulse wave velocity (PWV) is associated with cardiovascular mortality in dialysis patients [9-11].

Despite the recognition that both macro- and microvascular diseases could be independent contributors to progressive kidney failure [10, 12], the investigation of vascular contractile and endothelial function in the microcirculation in different CKD populations has been limited. Chronic kidney disease has been shown to alter the mechanosensitive and agonist-induced responses of peripheral arterioles, in part by interfering with NO-signaling mechanisms $[13,14]$. An increase in contractile response to norepinephrine and endothelin-1 has been demonstrated in isolated human uremic resistance arteries [14]. It has also been suggested that uremia treated with dialysis was not associated with altered sensitivity to agonists [15]. A number of studies which describe changes in contractile and endothelial function in microcirculation from different uremic models and vascular beds have been published $[8,16-18]$; however, controversy remains, perhaps due to the different disease models and disease stages studied.

The present study was designed to investigate the impact of uremia/the presence of impaired kidney function on the functional and mechanical properties of isolated resistance arteries from CKD patients. We hypothesized that vasomotor dysfunction and arterial stiffening would be present in the microcirculation from CKD patients, and that these perturbations would be more severe in patients on dialysis compared with those not on dialysis. Using tissue from both donors and recipients who were undergoing living kidney transplantation, we concluded that the endothelium-dependent and endothelium-independent relaxation in resistance vessels was severely sup- pressed in the nondialyzed patients. In contrast, the microvasculature in the dialyzed group showed increased contraction and stiffness. Uniquely, we correlated the in vitro measurements with in vivo measurements of vascular stiffness, and describe interesting inverse correlations with the endothelial function. All of these findings serve to increase our appreciation of the microvascular changes which occur in CKD.

\section{Methods}

Patient Recruitment and Study Design

Patients who were to undergo live donor kidney transplantation at the St. Paul's Hospital (Vancouver, B.C., Canada) were approached for participation in the study. The study was approved by the ethics board of Providence Health Care and the University of British Columbia. Written informed consent was obtained from donors and recipients prior to the surgery. They agreed to have small samples of skin segment dissected from the incision, and to undergo PWV measurements at the time of transplantation. Medical records were used to obtain demographic data as well as information regarding cardiovascular risk factors and renal function at the time of transplantation. The eGFR was calculated using the MDRD formula (table 1).

\section{Preparation of Patient Samples}

During live donor kidney transplantation, an ellipse of skin approximately $4-5 \mathrm{~mm}$ from the abdominal wall to a depth of $10-15 \mathrm{~mm}$ was dissected carefully from both donors and recipients. Skin segments were immediately placed into ice-cold RPMI solution in the presence of heparin and transported to the laboratory where it was placed in cold physiological Krebs' solution, $\mathrm{pH}$ of 7.4 , continuously aerated with a $5 \% \mathrm{CO}_{2} / 95 \% \mathrm{O}_{2}$ mixture. A series of experiments were conducted to test the functional and mechanical characteristics of the vessels obtained.

Note that the number of patient data is included in each figure. Although the total number of subjects is 62 , in some experiments there were missing data. This was because, given the nature of the tissue harvested from each patient, we were not able to dissect the same numbers of arterial segments from each individual. We had to take into consideration the healing and cosmetic result as well as the size of surgical scar. From some patients 8-10 segments were obtained, thus allowing us to perform all functional and stiffness measurement listed in the study. However, in those situations where only 2-3 segments were obtained, we selected specific experiments to perform. For example, we would perform $\mathrm{KCl}$, phenylephrine (PE), 5HT contraction, acetylcholine (ACh) relaxation, N-nitro-L-arginine methylester (L-NAME) pretreatment and stiffness measurement. When only limited numbers of vessel segments were obtained, we were unable to perform angiotensin/endothelin contraction, because their effects were not readily reversible.

With respect to the PWV, some data are missing due to the fact that some patients were not available for the PWV measurement (that is, some patients are living in other cities) prior to transplantation surgery. 
Table 1. Demographics and clinical features of the patients and living donors

\begin{tabular}{|c|c|c|c|c|}
\hline & $\begin{array}{l}\text { Donor } \\
(n=27)\end{array}$ & $\begin{array}{l}\text { Nondialysis } \\
(\mathrm{n}=15)\end{array}$ & $\begin{array}{l}\text { Dialysis } \\
(\mathrm{n}=20)\end{array}$ & $\mathrm{p}$ value \\
\hline Female, \% & 70.4 & 26.7 & 45.0 & 0.28 \\
\hline Age, years & $51 \pm 2.3$ & $53 \pm 6.2$ & $55 \pm 3.0$ & 0.75 \\
\hline Creatinine, $\mu \mathrm{M}$ & $81.4 \pm 3.73$ & $423 \pm 33.7$ & NA & NA \\
\hline $\mathrm{eGFR}, \mathrm{ml} / \mathrm{min} / 1.73 \mathrm{~m}^{2}$ & $74.6 \pm 2.59$ & $13.6 \pm 1.15$ & NA & NA \\
\hline Diabetes, $\%$ & 0 & 7 & 20 & 0.28 \\
\hline Hypertension, \% & 0 & 100 & 100 & NA \\
\hline Hyperlipidemic, \% & 0 & 47 & 25 & 0.19 \\
\hline Smokers, \% & 15 & 20 & 25 & 0.74 \\
\hline Calcium, mM & not collected & $2.34 \pm 0.04$ & $2.39 \pm 0.04$ & 0.34 \\
\hline Phosphate, mM & not collected & $1.66 \pm 0.11$ & $1.65 \pm 0.12$ & 0.95 \\
\hline PTH, pM & not collected & $37.1 \pm 7.6$ & $39.3 \pm 8.9$ & 0.86 \\
\hline Hemoglobin & $130 \pm 2.6$ & $112 \pm 2.9$ & $120 \pm 3.0$ & 0.07 \\
\hline Glucose, mM & $5.1 \pm 0.3$ & $6.3 \pm 0.4$ & $8.2 \pm 2.1$ & 0.44 \\
\hline Cholesterol, mM & $5.2 \pm 0.5$ & $4.8 \pm 0.4$ & $4.6 \pm 0.8$ & 0.79 \\
\hline $\mathrm{LDL}, \mathrm{mM}$ & $3.2 \pm 0.4$ & $3.1 \pm 0.5$ & $2.8 \pm 0.8$ & 0.77 \\
\hline Triglyceride, mM & $1.2 \pm 0.1$ & $1.7 \pm 0.2$ & $1.9 \pm 0.2$ & 0.38 \\
\hline Length of dialysis, months & 0 & 0 & $37.6 \pm 9.7$ & NA \\
\hline Previous kidney transplant, $\%$ & 0 & 13.3 & 10.0 & 0.77 \\
\hline Months since GFR $<30$ & 0 & $78.4 \pm 25.6$ & $68.2 \pm 10.8$ & 0.69 \\
\hline Months since 1st nephrologist consultation & 0 & $141 \pm 32.0$ & $104 \pm 16.9$ & 0.27 \\
\hline ACE inhibitor, $\%$ & 0 & 33.3 & 15.0 & 0.21 \\
\hline $\mathrm{ARB}, \%$ & 0 & 13.3 & 20.0 & 0.62 \\
\hline$\beta$-Blocker, $\%$ & 0 & 40.0 & 35.0 & 0.77 \\
\hline Calcium channel blocker, $\%$ & 0 & 66.7 & 20.0 & $0.004^{*}$ \\
\hline Aspirin, \% & 3.7 & 26.7 & 50.0 & 0.17 \\
\hline Statin, $\%$ & 0 & 46.7 & 25.0 & 0.19 \\
\hline
\end{tabular}

$\mathrm{p}$ values show statistical differences between the living kidney donors and recipients using one-way ANOVA. ${ }^{*} \mathrm{p}<0.05$. NA $=$ Not available.

\section{Isometric Force Measurement}

Resistance-sized skin arterioles (SkA; carefully dissected from the subcutaneous fat layer; internal diameter: $120 \pm 5 \mu \mathrm{m})$ were mounted isometrically in a small vessel myograph (A/S Danish Myotechnology, Aarhus N, Denmark) for measuring generated force $[19,20]$. Vessel segments were stretched for $20 \mathrm{~min}$ at which the resting force was stabilized, and then were challenged twice with $80 \mathrm{mM} \mathrm{KCl}$ before experiments. PE (1 nM to $300 \mu \mathrm{M})$, endothelin-1 (1-700 nM), angiotensin-II (1-30 nM) and serotonin (1 nM to $1 \mu \mathrm{M}$ ) were added cumulatively to generate concentrationresponse curves. To evaluate the endothelium-dependent relaxation, vessels were precontracted with $3 \mu \mathrm{M}$ PE before making cumulative applications of ACh $(0.01 \mathrm{nM}$ to $100 \mu \mathrm{M})$. The percentage of relaxation compared to the maximal $\mathrm{PE}$-induced contraction was recorded at different concentrations of $\mathrm{ACh}$. The $\mathrm{pEC}_{50}$ values (negative logarithm of the concentration giving half the maximum response) were assessed for individual concentrationresponse curves by nonlinear regression analysis. Sodium nitroprusside (SNP; $0.1 \mathrm{nM}$ to $10 \mu \mathrm{M}$ ) was added to the PE-precontracted vessels to assess the endothelium-independent relaxation. To reveal the endogenous NO production, vessels were pre-incu- bated with L-NAME $(200 \mu \mathrm{M})$ for 30 min before PE-induced contraction. To assess whether removal of superoxide affected relaxation, SkA segments were pre-incubated with superoxide dismutase (SOD; 150 units $\mathrm{ml}^{-1}$ ) for $30 \mathrm{~min}$ before precontraction with PE $(3 \mu \mathrm{M})$, which was followed by the cumulative concentrations of acetylcholine.

\section{In vitro Arterial Stiffness Measurement}

Measurements of vessel elasticity were derived from stressstrain curves [19]. Briefly, in a small vessel myograph, a 2-mm vessel segment was stretched by increasing the distance between the 2 stainless wires, and held at each length for $3 \mathrm{~min}$. The procedure was repeated until the vessel was unable to maintain its tension. In the measurement of elasticity, strain increased exponentially as a function of the vessel diameter, eliciting a J-shaped curve. The equation of such an exponential growth is $Y=$ start $X$ $\exp (\mathrm{K} \times \mathrm{X})$, where $\mathrm{Y}$ is stress, $\mathrm{X}$ is strain and $\mathrm{K}$ is a rate constant, where $Y$ increases exponentially. Steeper slopes indicate increased stiffness and the value of $\mathrm{K}$ reflects a numeric indicator of the stiffness of vessels. 

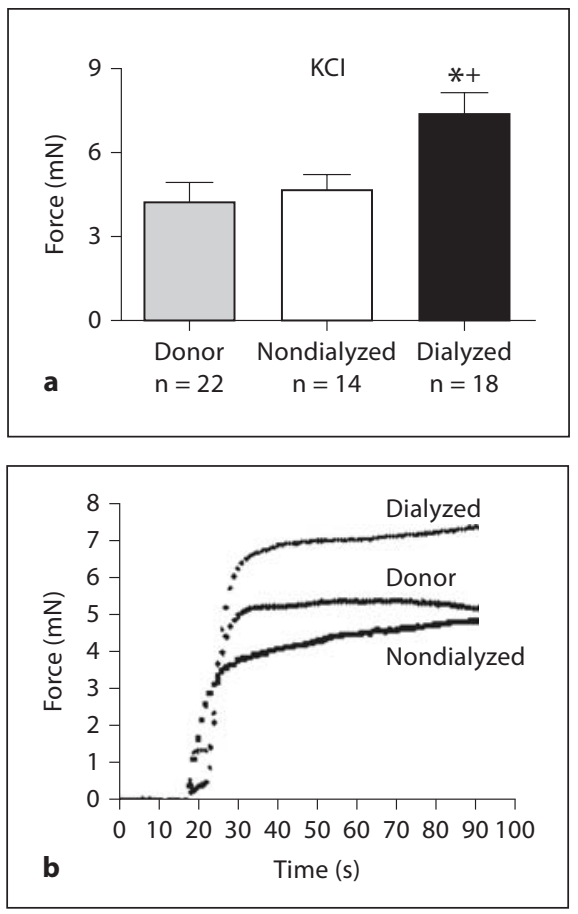

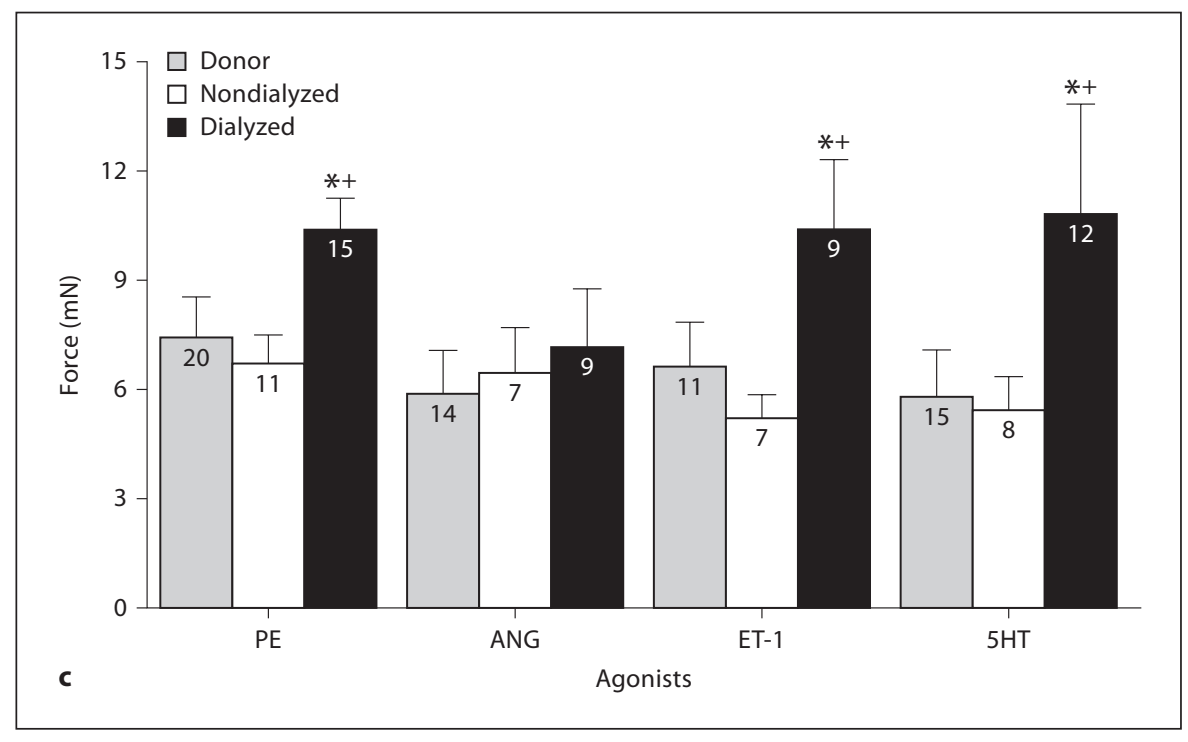

Fig. 1. Maximum force generated in SkA in response to $80 \mathrm{mM} \mathrm{KCl} \mathrm{(a,} \mathrm{b)} \mathrm{as} \mathrm{well} \mathrm{as} \mathrm{PE}$, angiotensin II (ANG), endothelin-1 (ET-1) and serotonin (5HT; c). Numbers in bars represent number of samples. ${ }^{*} \mathrm{p}<0.05$ vs. donor; ${ }^{+} \mathrm{p}<0.05$ vs. nondialyzed. b Representative traces showing the differences in $\mathrm{KCl}$-induced contraction in SkA.
In vivo $P W V$

All studies were conducted in a quiet, temperature-controlled room. After $15 \mathrm{~min}$ of supine rest, peripheral blood pressure was recorded. Using noninvasive methods, radial artery waveforms were obtained with a high-fidelity micromanometer (SPC-301; Millar Instruments, Houston, Tex., USA) applied at the radial pulse as previously described [21]. This generated an augmentation index, a composite measure of systemic arterial stiffness and wave-reflection amplitude or intensity (Sphygmocor; AtCor Medical, Sydney, N.S.W., Australia). Aortic (carotid to femoral) PWV was determined from measurements obtained from carotid and femoral pulses.

\section{Statistics}

Data were reported as mean \pm SD for normally distributed data (or median \pm SE for those with nonnormal distribution). Comparisons of unpaired data were performed using unpaired $t$ tests for parametric data, one-way ANOVA for multiple groups and $\chi^{2}$ tests for nominal data. Correlation plots were analyzed by linear regression; coefficient of determination was calculated from Pearson correlation. Statistical analysis and construction of concentration response curves were performed using GraphPad Prism software (version 4.03). Statistical significance was defined as $\mathrm{p}<0.05$.

\section{Results}

\section{Patient Cohort}

A total of 62 patients were studied, representing 27 donors and 35 recipients. All agreed to participate in the study between November 2007 and November 2008. Of the recipients, 15 were nondialysis, 8 were receiving peritoneal dialysis and 12 were on hemodialysis at the time of transplantation and thus tissue harvest and study (table 1). Besides the use of calcium channel blockers, there was no significant difference between nondialyzed and dialyzed groups.

\section{Enhanced Contractile Function in the \\ Microcirculation from Dialyzed Patients}

The vasoconstriction of SkA in response to KCl-induced depolarization and receptor-mediated stimulation were not significantly different between donor and nondialyzed groups. However, the depolarization response was markedly elevated in the dialyzed patients by $60 \%$ when compared with the nondialysis group (fig. 1a, b).

Although the sensitivity to $\mathrm{PE}$ (denoted as $\mathrm{pEC}_{50}$ values) was not significantly different among the 3 groups $($ donor $=6.41 \pm 0.11$; nondialyzed $=6.49 \pm 0.28$; dialyzed $=6.72 \pm 0.13)$, the maximal force $\left(\mathrm{E}_{\max }\right)$ induced by $3 \mu \mathrm{M}$ PE in the dialyzed SkA was increased by $47 \%$ compared with that of the nondialyzed group. Nevertheless, dialyzed SkA developed 50\% more force in response to endothelin- 1 and serotonin compared with the other 2 groups. However, the angiotensin II-stimulated contraction was not different among the 3 groups (fig. 1c). 

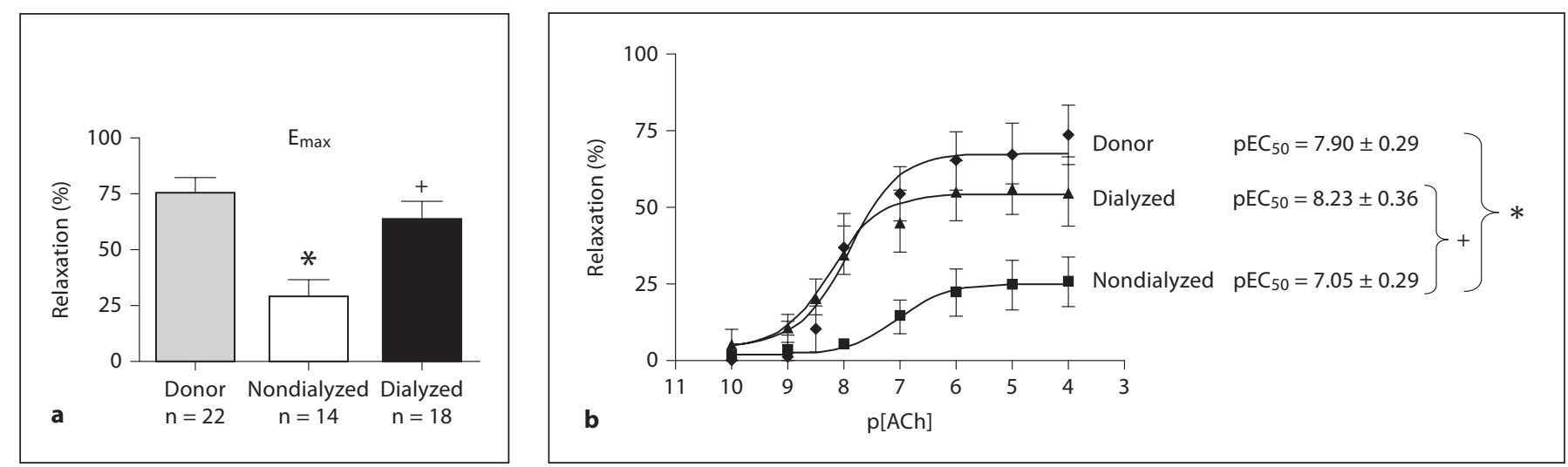

Fig. 2. a ACh-induced $\mathrm{E}_{\max }$ in SkA precontracted with $3 \mu \mathrm{M}$ PE. ${ }^{*} \mathrm{p}<0.05$ vs. donor; ${ }^{+} \mathrm{p}<0.05$ vs. nondialyzed. b Concentration-response curves of ACh-stimulated relaxation in SkA. The $\mathrm{pEC}_{50}$ values of ACh in each group are given. ${ }^{*} \mathrm{p}=0.02 ;^{+} \mathrm{p}=0.045$.

\section{Reduced Endothelium-Dependent and}

Endothelium-Independent Relaxation in the

Microcirculation from Nondialyzed Patients

The SkA from the dialyzed group had similar ACh relaxation response as that from the donors. The relaxation response was significantly $(\mathrm{p}<0.01)$ decreased in the nondialyzed group, with a $50 \%$ reduction in the $\mathrm{E}_{\max }$ compared with the other 2 groups (fig. 2a). Nevertheless, the sensitivity to $\mathrm{ACh}$ in the nondialyzed group $\left(\mathrm{pEC}_{50}=\right.$ $7.05 \pm 0.52$ ) was greatly reduced compared with dialyzed $\left(\mathrm{pEC}_{50}=8.23 \pm 0.36\right)$ and donor $\left(\mathrm{pEC}_{50}=7.90 \pm 0.29\right)$ groups, as indicated by the right shift of the ACh-concentration response curves (fig. $2 \mathrm{~b}$ ).

\section{Impact of Exogenous NO}

Endothelium-independent relaxation induced by the addition of SNP, an NO donor which bypasses endogenous NO production by endothelial cells, completely dilated PE-precontracted dialyzed and nondialyzed SkA. However, the $\mathrm{pEC}_{50}$ value of SNP was significantly reduced $(\mathrm{p}<0.01)$ in the nondialyzed group, indicating that the nondialyzed SkA had reduced sensitivity to exogenous NO (fig. 3).

\section{Impact of Superoxide Removal}

Excessive amount of reactive oxygen species, termed oxidative stress, contributes to vascular dysfunction and has been suggested to be associated with CKD progression. To test if oxidative stress contributed to the impaired ACh relaxation, SkA was incubated with $S O D$, the major antioxidant responsible for superoxide removal in the vasculature $[22,23]$. SOD greatly improved the ACh re-

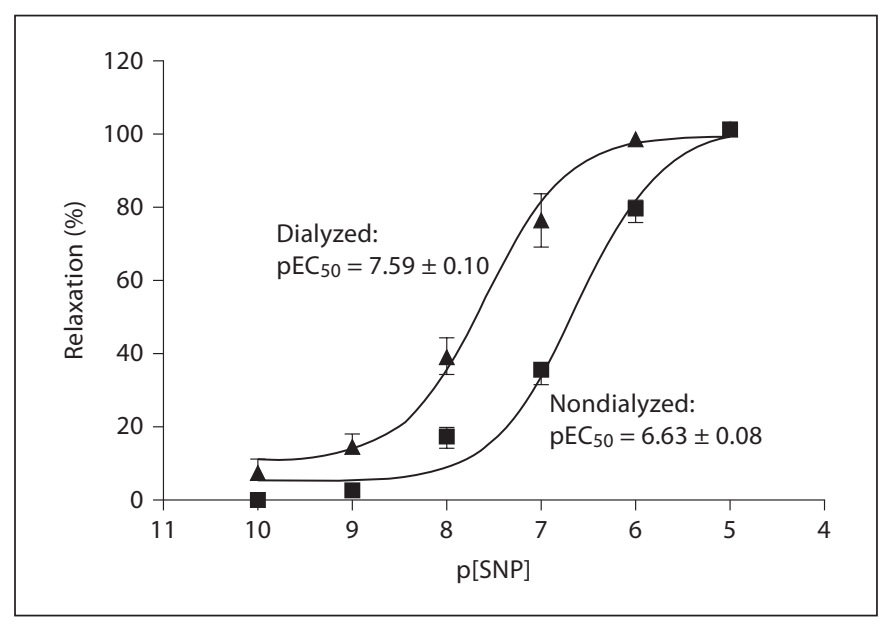

Fig. 3. Concentration-response curves of SNP-stimulated relaxation in nondialyzed and dialyzed SkA. The $\mathrm{pEC}_{50}$ values of SNP in each group are given.

laxation in the nondialyzed SkA, with a significant $(\mathrm{p}<$ 0.05) increase in both $\mathrm{ACh}_{\max }$ response and the $\mathrm{pEC}_{50}$ values (fig. 4a). Similar improvement was not observed in the dialyzed SkA (fig. 4b) and donor SkA (data not shown).

\section{Impact of Endogenous NO Removal}

To reveal the basal NO production and its impact on resting tension and agonist-induced contraction, vessels were pre-incubated with L-NAME, a specific inhibitor of NO synthase, before stimulation with PE. L-NAME pre- 

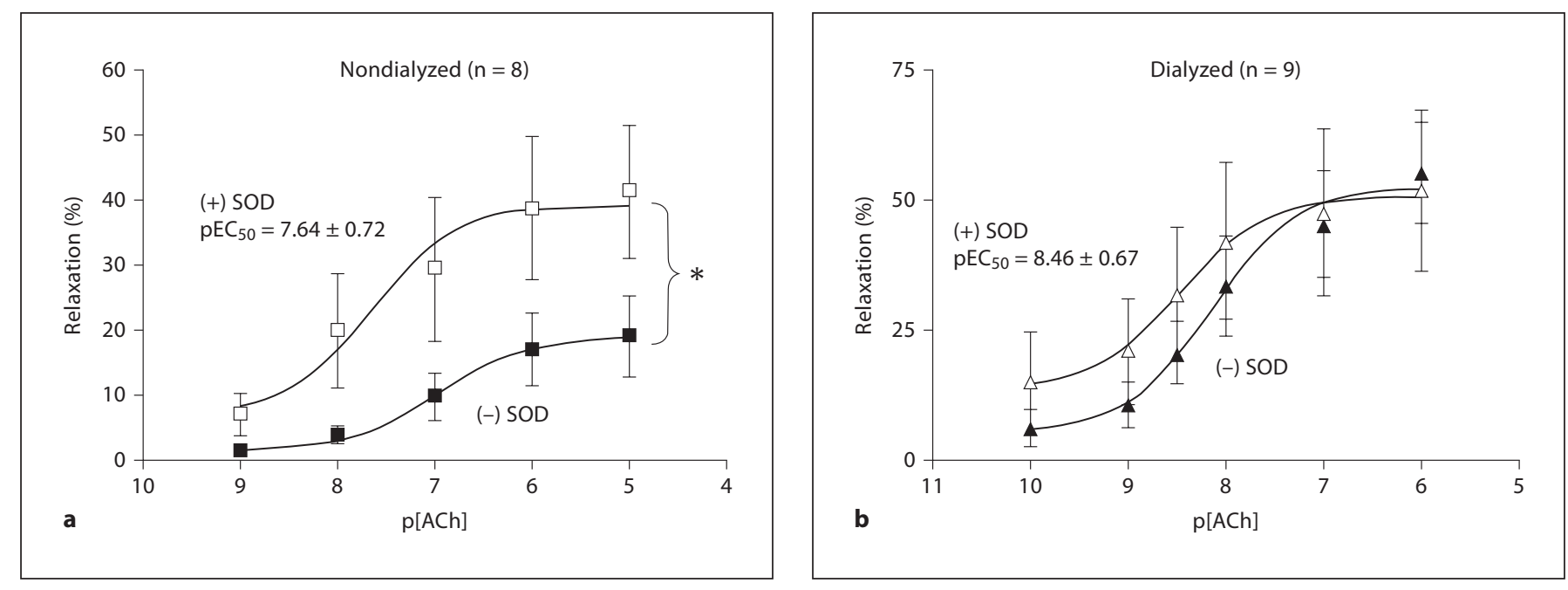

Fig. 4. Concentration-response curves of ACh-stimulated relaxation in the nondialyzed (a) and dialyzed SkA (b) with (+) or without (-) SOD incubation. ${ }^{*} \mathrm{p}<0.05$.

treatment significantly elevated the resting tension to $29.4 \pm 7.9 \mathrm{mN}$ in the donors $(\mathrm{p}=0.019)$ and $42.17 \pm 8.50$ $\mathrm{mN}$ in the nondialyzed group ( $\mathrm{p}=0.025)$, but had no effect in the dialyzed group (from $2.17 \pm 1.42$ to $4.38 \pm$ $2.81 \mathrm{mN} ; \mathrm{p}=0.49)$. L-NAME left shifted the concentration-response curve of $\mathrm{PE}$-stimulated contraction in the donor group, and the $\mathrm{EC}_{50}$ value was decreased by 2.4 fold (93.3 $\mathrm{nM}$ ) compared with that in the absence of L-NAME $(427 \mathrm{nM})(\mathrm{p}=0.05)$. However, in two recipient groups, L-NAME did not significantly alter the $\mathrm{EC}_{50}$ values of PE ( $p=0.65)$ (fig. 5).

\section{Increased Stiffness in the Microcirculation from \\ Dialyzed Patients}

In the in vitro mechanical property measurement, from the stress-strain curves, we found that the $\mathrm{K}$ value indicating vessel stiffness of dialyzed SkA was $60 \%$ stiffer than that of the nondialyzed and donor groups (fig. 6a, b). Additionally, the in vitro $\mathrm{K}$ value of SkA positively correlated with the PWV $\left(\mathrm{R}^{2}=0.301, \mathrm{p}=0.001\right.$; fig. $\left.6 \mathrm{c}\right)$.

\section{Vascular Stiffness and Endothelium-Dependent \\ Relaxation}

$\mathrm{NO}$-mediated endothelium-dependent relaxation in large artery is suggested to be important in regulating arterial stiffness [9-11]. In SkA, we studied the correlation between $\mathrm{ACh}$ response and PWV. In separated groups, the $\mathrm{R}^{2}$ for nondialysis was $0.17(\mathrm{p}=0.16)$, the $\mathrm{R}^{2}$ for dialysis was $0.23(\mathrm{p}=0.09)$ and the $\mathrm{R}^{2}$ for donor was $0.44(\mathrm{p}=0.004)$. However, attempting to elucidate the validation of PWV in assessing endothelial function in our subjects (donors and recipients), we reported the $\mathrm{R}^{2}$ from all subjects and the value is $0.28, \mathrm{p}=0.01$, showing the significant negative correlation between the $\mathrm{E}_{\max }$ of ACh relaxation and PWV (fig. 7).

\section{Discussion}

By comparing recipients and their kidney donors, and examining human microvasculature, we are the first to clearly report that CKD patients have perturbations in functional and mechanical properties of the microcirculation. Four novel observations arose from this study: (1) contractile function in response to depolarization and agonist (that is, PE, serotonin and endothelin-1) stimulation was significantly elevated in the vessels of dialyzed recipients; (2) endothelium-dependent and endotheliumindependent relaxation was impaired in the nondialyzed vessels; (3) SkA from dialyzed patients were stiffer than those from nondialyzed and donor groups; (4) endothelium-dependent relaxation was negatively correlated with vessel stiffness, and there was a significant correlation between in vivo and in vitro stiffness measurements. Thus, we have described a translational experiment which helps define microvascular changes in CKD and correlate those with composite measures of macrovascular stiffness in vivo.

The contractile function in response to membrane depolarization and agonist (that is, $\mathrm{PE}$, serotonin and endo- 
thelin-1) stimulation was markedly increased in the dialyzed SkA compared with that in the nondialyzed SkA, which demonstrated comparable responses with the donor (fig. 1). Since small vessels play an important role in regulating blood pressure and are sensitive to blood volume expansion, the increased sensitivity to membrane depolarization and agonist stimulation may be related to aberrant control of blood pressure and body fluid in the dialyzed patients. The increased plasma levels of vasoconstrictors, that is, endothelin-1, serotonin and norepinephrine, have been reported in end-stage CKD patients, which could result from decreased metabolic clearance rate, and stimulated synthesis caused by exaggerated sympathetic nervous activity, hypoxia, hemodynamic shear stress, increased blood pressure and other promoter cytokines present in uremia [24-32]. There was remarkable contraction in response to endothelin-1 (fig. 1c) $[14,33]$; however, a reduced expression of endothelin-1 receptor has been suggested in the vasculature, probably resulting from the prolonged exposure to the excessive secretion of endothelin-1 [34]. The increased plasma, urinary and vascular levels of endothelin-1 were correlated with blood pressure and the degree of renal damage (proteinuria, creatinine and glomerular sclerosis) [32, 35]. The exaggerated endothelin-1 response has been suggested to be associated with elevated PWV, left ventricular hypertrophy, prevalence of atherosclerotic plaques and arterial intima-media thickening in CKD patients [26, 36]. In dialysis patients, the high serotonin response may implicate platelet and coagulation abnormalities, hypoand hypertension [27], and the increased reactivity to serotonin could be due to its interaction with sympathetic nerves [33]. High circulating level of norepinephrine would predict adverse cardiovascular outcomes among hemodialysis patients and is strongly associated with left ventricular concentric hypertrophy and left ventricular systolic dysfunction $[29,30]$. The comparable angiotensin II-induced contraction between donor and recipient groups agreed with the previous studies [37,38], but it appeared to be conflicting since angiotensin II is believed to be one of the important vasoconstrictors causing hypertension in CKD. Mechanical forces including pressure and shear stress could regulate the production of angiotensin II [39]. As the hemodynamic shear stress may vary between healthy and CKD resistance arteries, we believed that it could affect the local angiotensin II level, receptor expression and its downstream vascular responses [40]. Nevertheless, since our recipient cohorts were well enough to undergo kidney transplantations, their cardiovascular risk burden was relatively lower

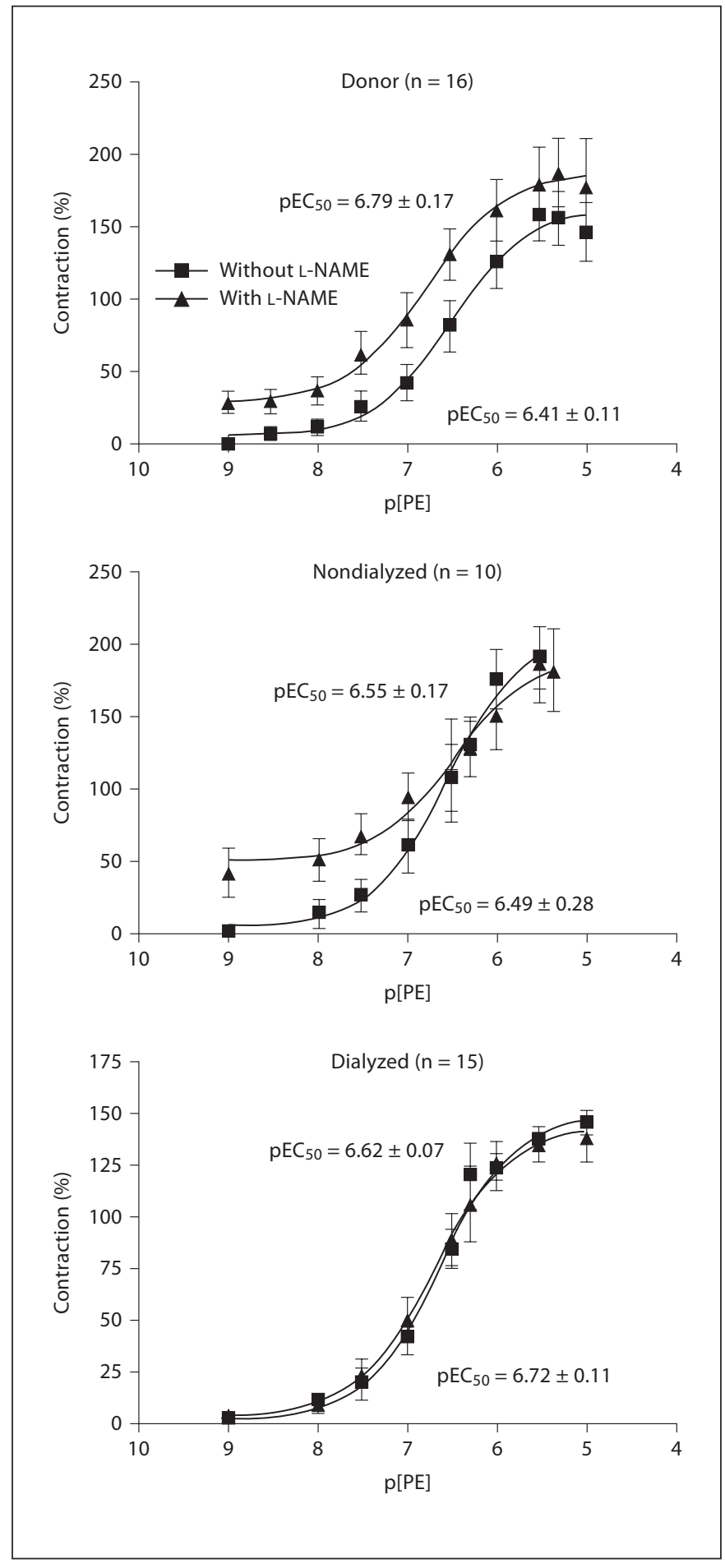

Fig. 5. Effect of L-NAME pretreatment on the concentration-response curves of PE-induced contraction in the SkA from donors, nondialyzed and dialyzed recipients. 

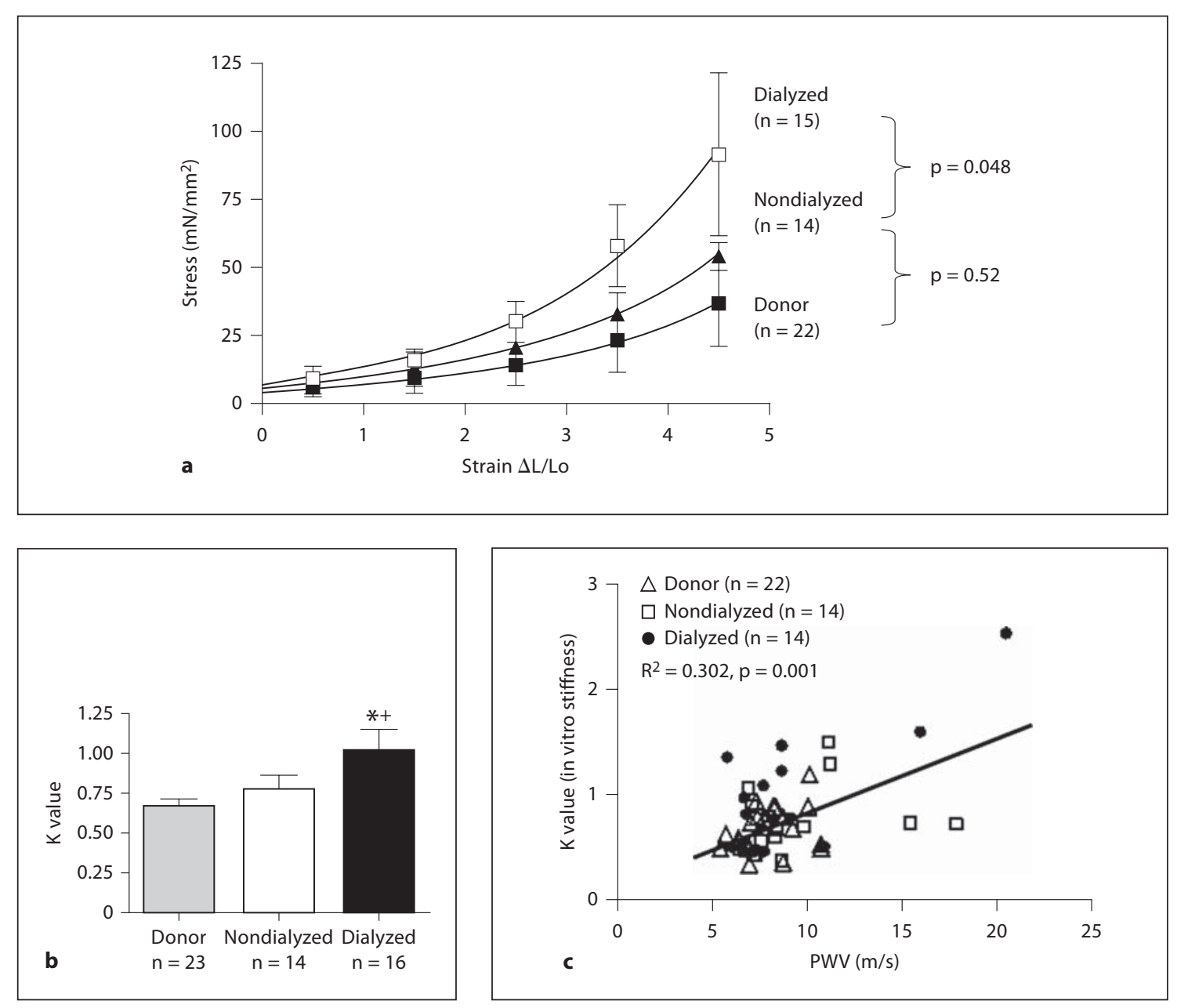

Fig. 6. In vitro and in vivo measurements of arterial stiffness. a Stress-strain curves of SkA. Equation of the exponential growth is $\mathrm{Y}=$ start $\times \exp (\mathrm{K} \times \mathrm{X})$. $\mathrm{Y}$ increases exponentially with rate constant $\mathrm{K}$. Stiffer vessel has larger slope and therefore larger K value. $\mathbf{b}$ Values of $\mathrm{K}$ from SkA. ${ }^{*} \mathrm{p}<0.05 \mathrm{vs}$. donor; ${ }^{+} \mathrm{p}<0.05 \mathrm{vs}$. nondialyzed. c Correlation between K value and PWV in all subjects.

compared with the long-term dialysis patients. We speculate that their renin-angiotensin system could be well controlled by the use of various antihypertensive medications (table 1), resulting in no difference in the angiotensin II response among the 3 groups.

We assessed the bioavailability of NO in the microvasculature by ACh stimulation and L-NAME pre-incubation. The marked reduction in ACh-stimulated endothelium-dependent relaxation in the nondialyzed group (fig. 2) agreed with previous work which demonstrated a decreased relaxation to ACh in the cephalic veins from preemptive patients [41]. However, the elevation of resting tension in the nondialyzed SkA by L-NAME indicated the presence of basal NO in the microcirculation, while the unresponsiveness to L-NAME in the dialyzed group suggested the absence of basal NO production (fig. 5). This differential NO bioavailability implicates the level of endothelial dysfunction and the deterioration of vascular health during CKD progression: from nondialysis to dialysis status.

Endothelial dysfunction has been consistently demonstrated in conduit vessels of patients with renal failure, with a smaller defect seen in the resistance vasculature [14]. However, a recent study demonstrated the prognostic role of endothelial dysfunction in resistance arteries from the population with high cardiovascular risk [5]. A noninvasive laser Doppler flowmetry functional testing of endothelium-dependent microvascular reactivity also 
Fig. 7. Correlation between PWV and the maximum ACh-induced relaxation in the 3 groups. The correlation was significant in all studied subjects.

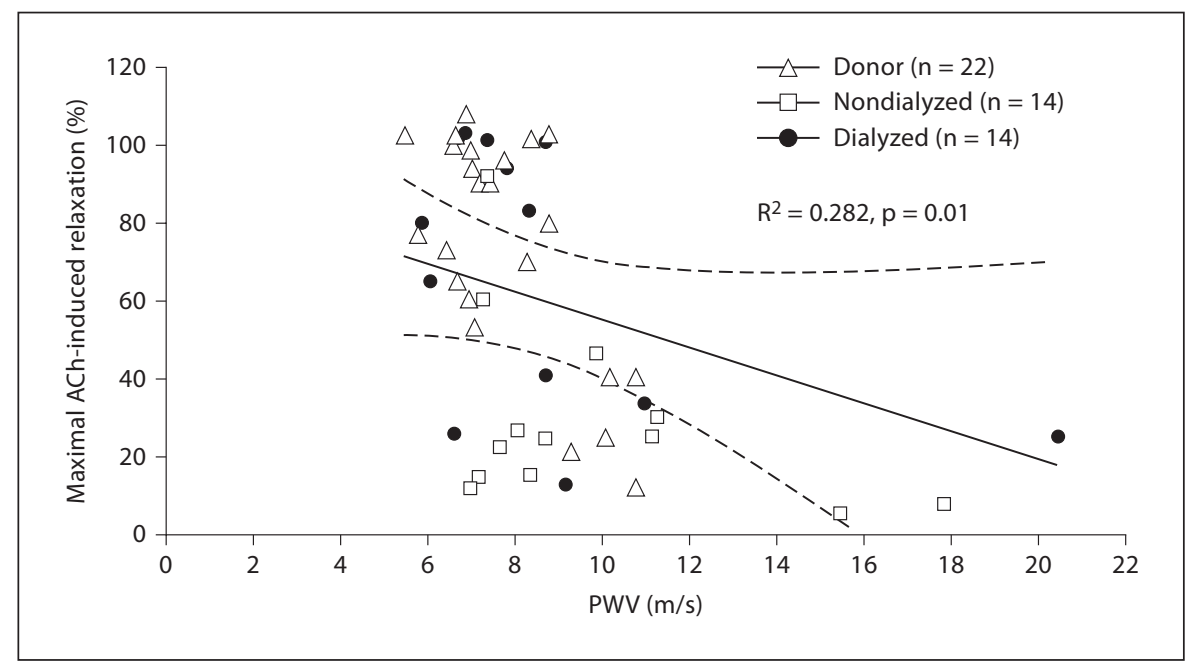

suggested that the microvascular reactivity offers a sensitive characterization of endothelial dysfunction [42]. We believe that further studies are required to assess endothelial function in individuals with GFR between 50 and $80 \mathrm{ml} / \mathrm{min}$ to determine the level at which endothelial dysfunction is induced.

The observation of normal endothelium relaxation in the dialyzed SkA is interesting and in conflict with current beliefs that CKD-5 patients have blunted/poor endothelial function. This apparent discordance can be explained in 3 ways. (1) Endothelial function is also modulated by shear stress, a factor dependent on flow that cannot be simulated in the current study. (2) In the nondialyzed group, calcium channel blockers are the preferred medication. Several studies have demonstrated that the effect of different antihypertensive drugs on vascular structure is not the same, with those interfering with the renin-angiotensin system being more effective $[43,44]$. (3) It has been shown that physiological flow is reduced in the skin microcirculation of uremics, and this abnormality is rapidly corrected by hemodialysis [45]. Besides, dialysis could remove dimethyl L-arginine and $\mathrm{N}(\mathrm{G})$-monomethyl-L-arginine, an inhibitor of NO synthesis, and thereby improve endothelial relaxation [46].

The impaired endothelium-dependent relaxation in the nondialyzed SkA, interestingly, could be improved by incubation with SOD (fig. 4a). Excessive amount of reactive oxygen species, termed oxidative stress, would contribute to vascular dysfunction in diabetes, heart failure, hypercholesterolemia, hypertension and chronic renal disease. Endothelial function has been shown to be improved by antioxidants, such as SOD, melatonin as well as vitamins $\mathrm{C}$ and $\mathrm{E}[22,23]$. Accumulation of oxidative stress is caused by an imbalance between the production and neutralization of reactive oxygen species. SOD is the major endogenous antioxidant responsible for superoxide removal. Oxidative stress may cause endothelial dysfunction through several direct and indirect pathways, the most well-known of which is the scavenging of NO by superoxide. Superoxide radicals bind to $\mathrm{NO}$ at a rate 3 times faster than they bind to SOD; therefore, excess superoxide production would increase the rate of NO degradation [23]. This also explained the reduced sensitivity to SNP-stimulated relaxation in the nondialyzed SkA as the exogenous NO would readily be neutralized by the augmented amount of reactive oxygen species.

Although endothelial dysfunction in nondialyzed patients may be reversed by dialysis, the increased stiffness (fig. 6a, b) involving the long-term modification of vascular remodeling may not be readily reversed. There is a pronounced intimal thickening and enhanced calcification of the internal elastic lamella in uremic patients, and these intrinsic degenerative changes of the arterial wall reduce vessel distensibility [47]. The elevated peripheral vascular stiffness and impaired endothelial function may increase cardiac afterload and further impair cardiac function in CKD patients. In addition, arterial stiffness is characterized by very steep volume-pressure relationship and is associated with hemodynamic instability in dialyzed patients. This explains that small blood volume increase could produce abnormally high pressure while small decrease in blood volume could cause hypotension.

We also demonstrated the statistically significant correlation between the in vitro assessment of small vessel 
stiffness and the in vivo large vessel PWV (fig. 6c). The weak correlation could be due to the fact that the PWV was used to measure the stiffness of large muscular artery, while the in vitro stiffness as indicated by the $\mathrm{K}$ value was performed on the skin resistance-sized artery. Irrespective, our additional finding that PWV was negatively related to endothelial function in vitro (fig. 7) supports the current practice that PWV measurements are useful tools by which to assess vascular health [21].

We acknowledge the limitations of this study. (1) All recipients are hypertensive. That clustering of cardiovascular risk factors may have synergistic deleterious effects on the vasculature deserves further investigation [5]. (2) Although the types of dialysis, that is, peritoneal and hemodialysis, could contribute to different clinical outcomes [48], in this study we combined peritoneal and hemodialysis for emphasizing the alterations in microvasculature during CKD progression. (3) Both the nature of the population studied (transplant eligible) and the crosssection design may bring some bias. Since it has been shown that reduced endothelial function is a predictor of cardiovascular events in dialyzed patients, it is possible that dialyzed patients with severe microvascular endothelial dysfunction had already died and the dialyzed patients of this study were survivors. Such a selection bias can explain the seemingly favorable results on the endothelial function from the dialyzed recipients presented herein.
In conclusion, using human tissue, we demonstrate the differential aberrations in vascular function between 2 groups of CKD patients, those exposed and not exposed to dialysis, but both well enough to receive kidney transplantations. The findings raise questions as to the possible impact of dialysis treatment on the microvascular function. The optimal timing of preemptive transplantation remains problematic: these results add interesting insights into vascular health in these patients that may impact on future perspectives. In clinical practice, monitoring the integrity of microcirculation may be helpful, though technically difficult, to assist in diagnosis, risk stratification and monitoring disease progression. The ability to investigate the microvascular structure and function is important in improving our understanding of pathophysiological processes in CKD and the related cardiovascular disease.

\section{Acknowledgments}

This study was supported by an operating grant from the Kidney Foundation of Canada. A.W.Y.C. is the recipient of a Michael Smith Foundation for Health Research/St. Paul's Hospital Foundation Trainee Award. H.H.C.Y. is the recipient of a Michael Smith Foundation for Health Research Junior Trainee Award and NSERC: Alexander Graham Bell Canada Graduate Scholarship.

\section{References}

1 Krentz AJ, Clough G, Byrne CD: Interactions between microvascular and macrovascular disease in diabetes: pathophysiology and therapeutic implications. Diabetes Obes Metab 2007;9:781-791.

-2 Struijker-Boudier HA, Rosei AE, Bruneval P, Camici PG, Christ F, Henrion D, Lévy BI, Pries A, Vanoverschelde JL: Evaluation of the microcirculation in hypertension and cardiovascular disease. Eur Heart J 2007;28: 2834-2840.

-3 Levy BI, Ambrosio G, Pries AR, StruijkerBoudier HA: Microcirculation in hypertension: a new target for treatment? Circulation 2001;104:735-740.

-4 Mulvany MJ, Aalkjaer C: Structure and function of small arteries. Physiol Rev 1990; 70:921-961.

-5 Rizzoni D, Porteri E, Boari GE, De Ciuceis C, Sleiman I, Muiesan ML, Castellano M, Miclini M, Agabiti-Rosei E: Prognostic significance of small-artery structure in hypertension. Circulation 2003;108:2230-2235.
6 Muiesan ML, Rizzoni D, Salvetti M, Porteri E, Monteduro C, Guelfi D, Castellano M, Garavelli G, Agabiti-Rosei E: Structural changes in small resistance arteries and left ventricular geometry in patients with primary and secondary hypertension. J Hypertens 2002;20:1439-1444.

7 Park JB, Schiffrin EL: Small artery remodeling is the most prevalent (earliest?) form of target organ damage in mild essential hypertension. J Hypertens 2001;19:921-930.

$\$ 8$ van Guldener C, Lambert J, Janssen MJ, Donker AJ, Stehouwer CD; Endotheliumdependent vasodilatation and distensibility of large arteries in chronic haemodialysis patients. Nephrol Dial Transplant 1997; 12(suppl 2):14-18.

-9 Blacher J, Guerin AP, Pannier B, Marchais SJ, Safar ME, London GM: Impact of aortic stiffness on survival in end-stage renal disease. Circulation 1999;99:2434-2439.

$\checkmark 10$ Schiffrin EL, Lipman ML, Mann JF: Chronic kidney disease: effects on the cardiovascular system. Circulation 2007;116:85-97.
11 Willum-Hansen T, Staessen JA, Torp-Pedersen C, Rasmussen S, Thijs L, Ibsen H, Jeppesen J: Prognostic value of aortic pulse wave velocity as index of arterial stiffness in the general population. Circulation 2006;113: 664-670.

12 Hayden PS, Iyengar SK, Schelling JR, Sedor JR: Kidney disease, genotype and the pathogenesis of vasculopathy. Curr Opin Nephrol Hypertens 2003;12:71-78.

13 Bagi Z, Hamar P, Antus B, Rosivall L, Koller A: Chronic renal failure leads to reduced flow-dependent dilation in isolated rat skeletal muscle arterioles due to lack of $\mathrm{NO}$ mediation. Kidney Blood Press Res 2003;26: 19-26.

14 Morris ST, McMurray JJ, Spiers A, Jardine AG: Impaired endothelial function in isolated human uremic resistance arteries. Kidney Int 2001;60:1077-1082 
15 Aalkjaer C, Pedersen EB, Danielsen H, Fjeldborg O, Jespersen B, Kjaer T, Sørensen SS, Mulvany MJ: Morphological and functional characteristics of isolated resistance vessels in advanced uraemia. Clin Sci (Lond) 1986; 71:657-663.

16 Joannides R, Bakkali EH, Le Roy F, Rivault O, Godin M, Moore N, Fillastre JP, Thuillez C: Altered flow-dependent vasodilatation of conduit arteries in maintenance haemodialysis. Nephrol Dial Transplant 1997;12: 2623-2628.

17 Jolma P, Kalliovalkama J, Tolvanen JP, Kööbi P, Kähönen M, Saha H, Pörsti I: Preserved endothelium-dependent but impaired $\beta$-adrenergic relaxation of the resistance vessels in experimental renal failure. Exp Nephrol 2002;10:348-354.

18 Thuraisingham RC, Raine AE: Maintenance of normal agonist-induced endothelium-dependent relaxation in uraemic and hypertensive resistance vessels. Nephrol Dial Transplant 1999;14:70-75.

19 Chung AW, Au Yeung K, Sandor GG, Judge DP, Dietz HC, van Breemen C: Loss of elastic fiber integrity and reduction of vascular smooth muscle contraction resulting from the upregulated activities of matrix metalloproteinase-2 and -9 in the thoracic aortic aneurysm in Marfan syndrome. Circ Res 2007;101:512-522.

20 Chung AW, Au Yeung K, Cortes SF, Sandor GG, Judge DP, Dietz HC, van Breemen C: Endothelial dysfunction and compromised eNOS/Akt signaling in the thoracic aorta during the progression of Marfan syndrome. Br J Pharmacol 2007;150:1075-1083.

-21 Laurent S, Cockcroft J, Van Bortel L, Boutouyrie P, Giannattasio C, Hayoz D, Pannier B, Vlachopoulos C, Wilkinson I, StruijkerBoudier H, European Network for Noninvasive Investigation of Large Arteries: Expert consensus document on arterial stiffness: methodological issues and clinical applications. Eur Heart J 2006;27:25882605.

-22 Cai H, Harrison DG: Endothelial dysfunction in cardiovascular diseases: the role of oxidant stress. Circ Res 2000;87:840-844.

23 Faraci FM, Didion SP: Vascular protection: superoxide dismutase isoforms in the vessel wall. Arterioscler Thromb Vasc Biol 2004; 24:1367-1373.

-24 Converse RL Jr, Jacobsen TN, Toto RD, Jost CM, Cosentino F, Fouad-Tarazi F, Victor RG: Sympathetic overactivity in patients with chronic renal failure. N Engl J Med 1992;327: 1912-1918.

\25 Farkas K, Nemcsik J, Kolossváry E, Járai Z, Nádory E, Farsang C, Kiss I: Impairment of skin microvascular reactivity in hypertension and uraemia. Nephrol Dial Transplant 2005;20:1821-1827.
26 Karakitsos D, Patrianakos AP, Parthenakis FI, Malliaraki N, Nikitovic D, Kyriazis J, Karabinis A, Groothoff JW, de Groot E, Fourtounas C, Daphnis E, Vardas PE: Altered proximal aortic stiffness and endothelin plasma levels in diabetic patients with end-stage renal disease. ASAIO J 2007;53: 343-350.

27 Kerr PG, Argiles A, Mion C: Whole blood serotonin levels are markedly elevated in patients on dialytic therapy. Am J Nephrol 1992;12:14-18.

28 Shichiri M, Hirata Y, Ando K, Emori T, Ohta K, Kimoto S, Ogura M, Inoue A, Marumo F: Plasma endothelin levels in hypertension and chronic renal failure. Hypertension 1990;15:493-496.

29 Zoccali C, Mallamaci F, Parlongo S, Cutrupi S, Benedetto FA, Tripepi G, Bonanno G, Rapisarda F, Fatuzzo P, Seminara G, Cataliotti A, Stancanelli B, Malatino LS: Plasma norepinephrine predicts survival and incident cardiovascular events in patients with endstage renal disease. Circulation 2002;105: 1354-1359.

30 Zoccali C, Mallamaci F, Tripepi G, Parlongo S, Cutrupi S, Benedetto FA, Cataliotti A, Malatino LS: Nor-epinephrine and concentric hypertrophy in patients with end stage renal disease. Hypertension 2002;40:41-46.

- 31 Yoshizumi M, Kurihara H, Sugiyama T, Takaku F, Yanagisawa M, Masaki T, Yazaki Y: Hemodynamic shear stress stimulates endothelin production by cultured endothelial cells. Biochem Biophys Res Commun 1989; 161:859-864.

- 32 Ottosson-Seeberger A, Ahlborg G, Hemsén A, Lundberg JM, Alvestrand A: Hemodynamic effects of endothelin-1 and big endothelin-1 in chronic hemodialysis patients. J Am Soc Nephrol 1999;10:1037-1044.

- 33 Büssemaker E, Passauer J, Reimann D, Schulze B, Reichel W, Gross P: The vascular endothelin system is not overactive in normotensive hemodialysis patients. Kidney Int 2002;62:940-948.

34 Hand MF, Haynes WG, Webb DJ: Reduced venous responsiveness to endothelin-1 but not noradrenaline in hypertensive chronic renal failure. Nephrol Dial Transplant 2001; 16:295-301.

35 Koyama H, Tabata T, Nishzawa Y, Inoue T, Morii H, Yamaji T: Plasma endothelin levels in patients with uraemia. Lancet 1989;1:991992.

36 Demuth K, Blacher J, Guerin AP, Benoit MO, Moatti N, Safar ME, London GM: Endothelin and cardiovascular remodelling in endstage renal disease. Nephrol Dial Transplant 1998;13:375-383.

37 Collis MG, DeMey C, Vanhoutte PM: Renal vascular reactivity in the young spontaneously hypertensive rat. Hypertension 1980;2: 45-52.
38 Kvist S, Mulvany MJ: Reduced medication and normalization of vascular structure, but continued hypertension in renovascular patients after revascularization. Cardiovasc Res 2001;52:136-142.

-39 Rieder MJ, Carmona R, Krieger JE, Pritchard KA Jr, Greene AS: Suppression of angiotensin-converting enzyme expression and activity by shear stress. Circ Res 1997;80:312319.

40 Henrion D, Kubis N, Lévy BI: Physiological and pathophysiological functions of the $\mathrm{AT}_{2}$ subtype receptor of angiotensin II: from large arteries to the microcirculation. Hypertension 2001;38:1150-1157.

41 Segarra G, Lluch P, Mauricio MD, Vila JM, Medina P, Martinez-León JB, Aldasoro M, Lluch S: Contractile hyporesponsiveness to norepinephrine of forearm veins in chronic renal failure. Am J Hypertens 2006;19:818822.

42 Kruger A, Stewart J, Sahityani R, O’Riordan E, Thompson C, Adler S, Garrick R, Vallance P, Goligorsky MS: Laser Doppler flowmetry detection of endothelial dysfunction in endstage renal disease patients: correlation with cardiovascular risk. Kidney Int 2006;70: 157-164.

43 Rizzoni D, Muiesan ML, Porteri E, Castellano M, Zulli R, Bettoni G, Salvetti M, Monteduro C, Agabiti-Rosei E: Effects of longterm antihypertensive treatment with lisinopril on resistance arteries in hypertensive patients with left ventricular hypertrophy. J Hypertens 1997;15:197-204.

44 Schiffrin EL, Deng LY: Structure and function of resistance arteries of hypertensive patients treated with a $\beta$-blocker or a calcium channel antagonist. J Hypertens 1996; 14: 1247-1255.

45 Rossi M, Cupisti A, Morelli E, Tintori G, Fabbri A, Battini S, Vagheggini G, Barsotti G: Laser Doppler flowmeter assessment of skin microcirculation in uremic patients on hemodialysis treatment. Nephron 1996;73: 544-548.

46 Vallance P, Leone A, Calver A, Collier J, Moncada S: Accumulation of an endogenous inhibitor of nitric oxide synthesis in chronic renal failure. Lancet 1992;339:572-575.

47 Barenbrock M, Spieker C, Laske V, Heidenreich S, Hohage H, Bachmann J, Hoeks AP, Rahn KH: Studies of the vessel wall properties in hemodialysis patients. Kidney Int 1994;45:1397-1400.

48 Jaar BG, Coresh J, Plantinga LC, Fink NE, Klag MJ, Levey AS, Levin NW, Sadler JH, Kliger A, Powe NR: Comparing the risk for death with peritoneal dialysis and hemodialysis in a national cohort of patients with chronic kidney disease. Ann Intern Med 2005;143:174-183. 